\title{
Effect of Covid-19 in Otorhinolaryngology Practice: A Review
}

\author{
Kanchan Grag $^{1} \cdot$ Kumar Shubhanshu ${ }^{2}$
}

Received: 11 May 2020/Accepted: 8 August 2020/Published online: 18 August 2020

(C) Association of Otolaryngologists of India 2020

\begin{abstract}
Otorhinolaryngological manifestations are common among patients suffering from COVID-19. This study provides a brief and precise review of the current knowledge regarding COVID-19 including disease transmission and clinical characteristics. This article aims to review the otolaryngologist experience treating patients in the cities where COVID 19 impact is most, and to propose appropriate protective measures while managing ENT patients. This is a retrospective study conducted in the Department of Otorhinolaryngology, Hind Institute of Medical Sciences, Ataria, Sitapur from 10 March 2020 to 4 May 2020. The most common otolaryngological symptoms of COVID-19 were cough, sore throat, and dyspnea. Rhinorrhea, nasal congestion and dizziness also seen in some of the patients. COVID-19 could also manifest as an isolated sudden hyposmia/anosmia. Upper respiratory tract (URT) symptoms were commonly observed in younger patients and usually appeared initially. They could be present even before the molecular confirmation of SARS-CoV-2. Otolaryngologists are at higher risk for SARS-CoV-2 infection as they cope with URT symptoms in OPD and while performing surgery in COVID-19 positive patients. Patients with cough, sore throat, dyspnea, hyposmia/anosmia and a history of travel to the region with confirmed COVID-19 patients, should be considered as potential COVID-19
\end{abstract}

Kumar Shubhanshu

shubhanshu0304@gmail.com

Kanchan Grag

kanchangarg68@gmail.com

1 Department of Pathology, Hind Institute of Medical Sciences, Sitapur, India

2 Department of Otorhinolaryngology, Hind Institute of Medical Sciences, Sitapur, India cases. An otolaryngologist should wear FFP3/N95 mask, glasses, disposable and fluid resistant gloves and gown while examining such individuals. ENT surgeries should be postponed if not urgent.

Keywords COVID-19 · URT · PPE

\section{Introduction}

The 2019 novel coronavirus disease (COVID-19) pandemic started in December 2019 in the city of Wuhan, Hubei province in China. It is a highly contagious zoonosis (with a reproductive number of 2.8 , which means that under preexisting conditions one case generates 2.8 new cases) produced by a beta coronavirus (SARS-CoV-2) that spreads from human-to-human, largely by respiratory secretions and occasionally by feces $[1,2]$. The infection spreads predominantly (87\%) in people with 30 to 79 years of age [3]. Usually it remains asymptomatic (81\%) or produce only mild symptoms, but $15 \%$ cases require hospitalization while some ( 3 to $4 \%$ ) require respiratory support in an intensive care unit (ICU) [3]. The death rate has been calculated between 0.39 and $4 \%$, but this depends upon patient's age and is much higher in above 70 year patient's $[1,3]$. The first reported physician fatality related to COVID-19 in Wuhan, China was that of an otolaryngology physician on 25 January 2020 [4]. In Wuhan epidemic statistics, $3.8 \%$ of the infected cases were health workers, among which $14.8 \%$ had severe disease, and the overall mortality rate was of $0.6 \%[1,3,5]$. In COVID-19 patients with known respiratory disease, protective measures are usually followed by surgeons. However, a significant number of patients do not have fever or respiratory symptoms (13-30\%), so surgeons should apply respiratory 
protective strategies in all patients. The classical symptoms of the infection are fever, dry cough, and shortness of breath. The symptoms rarely resemble a classical "cold" or with a runny nose that helps distinguish it from the common viral flu. Nonetheless, precautions must be taken for all patients with flu-like symptoms. Recent reports from around the world have shown that anosmia and dysgeusia are significant symptoms associated with the COVID-19 pandemic. Anosmia, in particular, has been seen in patients testing positive for the coronavirus with no other symptoms. For this reason, the American Academy of Otolaryngology (AAO-HNSF) has proposed that these symptoms be added to the list of screening tools for possible COVID-19 infection [6]. All procedures that have the potential to aerosolize aerodigestive secretions, such as nasolaryngoscopy, endotracheal intubation, noninvasive ventilation, endoscopic surgery, and high-speed handpieces or ultrasonic instruments, increase the risk of infection and should be avoided or employed only when mandatory $[1,7]$. There is no information regarding any potential risk for electrocautery smoke or transoral laser resection generated smoke but it would be reasonable to take appropriate precautions in these settings too. Due to the characteristics of the virus, the standard protective measures of daily workflow do not prevent the infection, and specific masks (N-95 or FFP2 or higher) or powered air-purifying respirator (PAPR), other personal protective equipment (PPE) and dedicated sterilization measures should be implemented to avoid the infection $[8,9]$.

\section{Material and Methods}

The is a retrospective study conducted in the Department of Otorhinolaryngology, Hind Institute of Medical Sciences, Ataria, Sitapur from 10 March 2020 to 4 May 2020. The patients attending the OPD were first sent to the Triage 0 where complaints are asked for any history of cough, fever, cold, travel to the infected area or outside INDIA. Once the history is taken, patient is sent to the Triage 1 i.e. fever clinic where patient's temperature is checked and complaints are noted and if patient found to be asymptomatic, they are sent to the OPDs of respective department. But once patient come to Ent OPD, proper measures needed like personal protective equipment's etc.

\section{Result}

COVID-19 patients mainly presents with dry cough, pain throat and myalgia, although every 3 to 4 patients out of 10 have same type of complaints and it was found more to be psychological complaints. Anorexia, dyspnea, sputum production, and myalgias are reported in more than $25 \%$ of cases. Sore throat, rhinorrhea, headaches, nausea and diarrhea are less frequent and are mainly observed in mild to moderate forms of the disease.

\section{Discussion}

Cough, dyspnea, sore throat, rhinorrhea, nasal congestion, throat congestion, tonsils edema, enlarged cervical lymph nodes or dizziness are symptoms that otolaryngologist could encounter while examining patients with COVID-19 [10-12]. It was recently reported that COVID-19 led to hyposmia/anosmia and taste disturbances. South Korea, China and Italy presented that a significant number of individuals with COVID-19 was affected by hyposmia/ anosmia. A few cases were also detected in Germany. There are also reports implying that COVID-19 may present as isolated anosmia. These patients could be the source of the rapid spread of COVID-19 [13].

\section{Recommendations for Clinical and Endoscopic Examination}

The risk of contamination is very high in upper respiratory examinations. In Chinese patients, SARS-Cov-2 was detected in $63 \%$ of nasopharyngeal swabs, in $46 \%$ of the fiberoptic bronchoscopic brush biopsies and in $93 \%$ of bronchoalveolar lavage fluid specimens. Higher viral loads were detected in the nose than in the throat. In spite of that, recommendations for clinical and endoscopic examination can be very controversial because adequate PPE to all staff involved in patient care cannot be available everywhere. Disruption of supply chains and depletion of stock of PPE can drive anxiety in health professionals [14-16]. Head and neck surgeons, otolaryngologists, maxillofacial surgeons, and anesthetists are at high risk of contamination and infection by SARS-CoV-2 when assisting patients with tracheostomy or performing a rhinoscopy or a laryngoscopy because of the generation of aerosols. Fortunately, tracheostomy is unlikely to be required for the majority of patients. All patients must be examined by ENT surgeon wearing PPE such as N95 or FFP2 mask or PAPR, gown, cap, eye protection, and gloves (Table 1) [4, 14]. For tracheostomy, all staff must keep PPE with a PAPR throughout the procedure [17].

\section{Operating on Patients with COVID-19 (Fig. 1)}

In preparation for the COVID-19 pandemic, Wong et al. [18] reviewed OR (operating room) outbreak response measures. Several recommendations can be implemented worldwide, others must be adapting according to the 
Table 1 Necessary personal protection equipment

Personal protection equipment

FFP2 facial mask

FFP3 facial mask (in case of maneuvers at high risk of generating aerosolized particles)

Disposable long sleeve waterproof coats, gowns, or Tyvek suits

Disposable double pair of nitrile gloves

Protective goggles or visors, Disposable head caps, Disposable long shoe covers

Alcoholic hand hygiene solution

FFP filtering face piece

resource availability. An OR with a negative pressure environment is ideal to reduce dissemination of the virus. A high frequency of air changes (25 per hour) reduces viral load within the OR. Separate ORs can be designated for surgery in patients suspected or confirmed to have COVID19. Each OR must have its own ventilation system with an integrated high-efficiency particulate air filter. Traffic and flow of contaminated air can be minimized by locking all doors to the OR during surgery, with only one possible route for entry and exit. All health care personnel must be trained in the use of PPE. Postoperative visits must be suspended and replaced by phone calls to reduce movement of staff around the hospital. Ti et al. [19] recommend that an OR with a negative pressure environment with separate access must be used to operate suspected or confirmed cases of COVID-19 infection. They also advocate that the same room and the same anesthesia machine should be used for all COVID-19 patients during the epidemic. During the surgical procedure, a runner wearing PPE is stationed outside the OR in case other drugs or equipment are needed. In Indian setup, this will be a big challenge to set up separate OR as per norms for every hospital, medical colleges and for private practitioners. Chlorine-containing disinfectant $(2000 \mathrm{mg} / \mathrm{L})$ was used to clean the OR floor and wipe the surface of all reusable medical equipment. All medical devices, such as surgical instruments, were soaked for $30 \mathrm{~min}$ in $2000 \mathrm{mg} / \mathrm{L}$ chlorine-containing disinfectant, then sealed and collected into double-layer disposable medical waste bags in the cleaning room and sent to the designated disinfection area. After the OR was cleaned, the air purification system was shut down after $30 \mathrm{~min}$ of continuous operation of negative pressure laminar flow. Then, an ultra-low volume of $3 \%$ hydrogen peroxide $(20-30 \mathrm{~mL} / \mathrm{m})$ was used to closed fumigate the OR for $2 \mathrm{~h}$. Finally, the negative pressure ventilation of the OR was turned on again. All medical staff who were involved in surgical procedure were required to have a SARS-CoV-2 virus detection test (reverse transcription polymerase chain reaction of nasopharyngeal swabs) and CT scans once every 2 weeks [20].

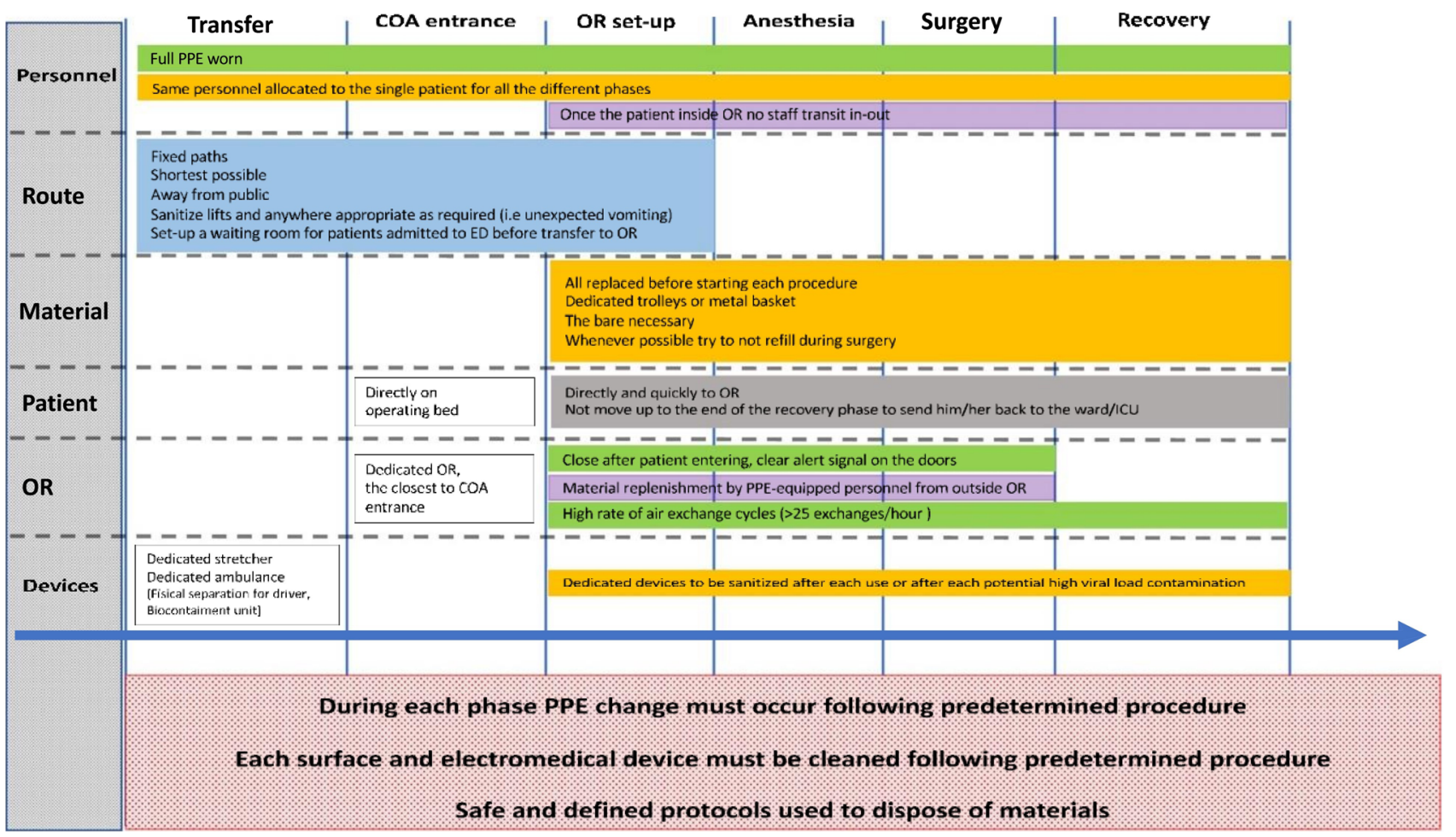

Fig. 1 COVID -19 surgical patients management flowchart 


\section{Conclusions}

The world is experiencing an unprecedented challenge during the COVID-19 pandemic. Lessons learned include increased risks of transmission to otolaryngologists, oral maxillofacial surgeons, dentists, and anesthesiologists; and tactics to limit the risk of spread. In our sector it is required to know about COVID-19 but its our job to train the staff and the patients attending the OPDs or any other procedures. An otolaryngologist should wear FFP3/N95 mask, glasses, disposable and fluid resistant gloves and gown while examining such individuals. ENT surgeries should be postponed if not urgent.

Funding None.

\section{Compliance with Ethical Standards}

Conflict of interest None.

\section{References}

1. Meng L, Hua F, Bian Z (2019) Coronavirus disease (COVID-19): emerging and future challenges for dental and oral medicine. J Dent Res 2020:22034520914246

2. Chan KW, Wong VT, Tang SCW (2020) COVID-19: an update on the epidemiological, clinical, preventive and therapeutic evidence and guidelines of integrative Chinese-Western medicine for the management of 2019 novel coronavirus disease. Am J Chin Med 48(3):737-762

3. Wu Z, McGoogan JM (2020) Characteristics of and important lessons from the coronavirus disease 2019 (COVID-19) outbreak in China: summary of a report of 72314 cases from the Chinese center for disease control and prevention. JAMA 323:1239

4. Chan Y, Wong W, Lam W (2020) Practical aspects of otolaryngologic clinical services during the 2019 novel coronavirus epidemic. An experience in Hong Kong. JAMA. Otolaryngol Head Neck Surg. https://doi.org/10.1001/jamaoto.2020.0488

5. Wang J, Zhou M, Liu F (2020) Exploring the reasons for healthcare workers infected with novel coronavirus disease 2019 (COVID-19) in China. J Hosp Infect. https://doi.org/10.1016/j.jhin.2020.03.002

6. Joob B, Wiwanitkit V (2020) COVID-19 in medical personnel: observation from Thailand. J Hosp Infect 104:453
7. Patel Z, Fernandez-Miranda J, Hwang P, et al (2020) Precautions for Endoscopic Trans nasal Skull Base Surgery during the COVID-19 Pandemic. Accessed March 24, 2020

8. Rimmer A (2020) Covid-19: what's the current advice for UK doctors? BMJ 368:m978

9. Schwartz J, King CC, Yen MY (2020) Protecting health care workers during the COVID-19 coronavirus outbreak-lessons from Taiwan's SARS response. Clin Infect Dis 71(15):858-860

10. Huang C, Wang Y, Li X, Ren L, Zhao J, Hu Y, Zhang L, Fan G, Xu J, Gu X, Cheng Z, Yu T, Xia J, Wei Y, Wu W, Xie X, Yin W, Li H, Liu M, Xiao Y, Gao H, Guo L, Xie J, Wang G, Jiang R, Gao Z, Jin Q, Wang J, Cao B (2020) Clinical features of patients infected with 2019 novel coronavirus in Wuhan. China Lancet 395(10223):497-506

11. Liu K, Fang YY, Deng Y, Liu W, Wang MF, Ma JP, Xiao W, Wang YN, Zhong MH, Li CH, Li GC, Liu HG (2020) Clinical characteristics of novel coronavirus cases in tertiary hospitals in Hubei Province. Chin Med J (Engl) 133(9):1025-1031

12. Xu XW, Wu XX, Jiang XG, Xu KJ, Ying LJ, Ma CL, Li SB, Wang HY, Zhang S, Gao HN, Sheng JF, Cai HL, Qiu YQ, Li LJ (2020) Clinical findings in a group of patients infected with the 2019 novel coronavirus (SARS-Cov-2) outside of Wuhan, China: retrospective case series. BMJ 368:m606

13. Hopkins C, Kumar N (2020) Loss of sense of smell as marker of COVID-19 infection (letter). ENT UK website

14. Wang W, Xu Y, Gao R et al (2020) Detection of SARS-CoV-2 in different types of clinical specimens. JAMA 323:1843-1844

15. Zou L, Ruan F, Huang M et al (2020) SARS-CoV-2 viral load in upper respiratory specimens of infected patients. N Engl J Med 382:1177-1179

16. Hopman J, Allegranzi B, Mehtar S (2020) Managing COVID-19 in low-and middle-income countries. JAMA 323:1549-1550

17. Koh D (2020) Occupational risks for COVID-19 infection. Occup Med 70:3-5

18. Wong J, Goh QY, Tan Z et al (2020) Preparing for a COVID-19 pandemic: a review of operating room outbreak response measures in a large tertiary hospital in Singapore. Can J Anaesth 67(6):732-745

19. Ti LK, Ang LS, Foong TW, Ng BSW (2020) What we do when a COVID-19 patient needs an operation: operating room preparation and guidance. Can J Anaesth 67:756-758

20. Chen R, Zhang Y, Huang L, Cheng BH, Xia ZY, Meng QT (2020) Safety and efficacy of different anesthetic regimens for parturients with COVID-19 undergoing Cesarean delivery: a case series of 17 patients. Can J Anaesth 67(6):655-663

Publisher's Note Springer Nature remains neutral with regard to jurisdictional claims in published maps and institutional affiliations. 